\title{
A VERTIGEM, AS DESRAZÕES E A MODELAGEM DO TEMPO COMO FENÔMENOS NATURAIS À CONSTRUÇÃO DO CONHECIMENTO - POR UMA EPISTEMOLOGIA DA EXPERIÊNCIA ESTÉTICA
}

\author{
VERTIGO, UNREASONS AND MODELING OF TIME, AS NATURAL PHENOMENA FOR \\ THE CONSTRUCTION OF KNOWLEDGE - FOR AN EPISTEMOLOGY OF AESTHETIC \\ EXPERIENCE
}

\author{
VERTIGO, SINRAZONES Y EL MODELADO DEL TIEMPO, COMO LOS FENÓMENOS \\ NATURALES PARA LA CONSTRUCCIÓN DEL CONOCIMIENTO - PARA UNA \\ EPISTEMOLOGÍA DE LA EXPERIENCIA ESTÉTICA
}

Eduardo Duarte Doutor

Professor adjunto do Dept. de Comunicação Social da Universidade Federal de Pernambuco. edwarte@terra.com.br

\begin{abstract}
Resumo: As ciências contemporâneas fazem surgir uma forma de construção do conhecimento não apenas a partir da análise de estruturas lógicas e racionais, mas também com a presença dos campos sensíveis, vistos anteriormente como desrazões, como a loucura, a poesia e a fé. Nesse sentido, a experiência estética cria mundos de sensibilidade ao artista e ao cientista promovendo a vivência de temporalidades, rupturas vertiginosas de sistemas e emergências não apenas de novos paradigmas de ciências, mas de novos campos de experimentação artística, como as que se pode observar ao longo do século 20.
\end{abstract}

Palavras-Chave: Desrazão 1.Vertigem 2. Construção de conhecimento 3.

Abstract: The contemporary sciences give rise a way of building knowledge not only from logical structures and rational analysis, but also from the presence of sensitive fields, previously seen as unreasons, like madness, poetry and faith. In this sense, aesthetic experience creates worlds of sensitivity to artist and scientist, it promotes experience of temporalities, breaks of systems, not only for the rising of new paradigms of science, but also new fields of artistic experimentation, as we can see in the 20th century.

Keywords: Unreason 1.Vertigo 2. Building of knowledge 3. 
Resumen: Las ciencias contemporáneas dan lugar a una forma de construcción de conocimiento no sólo del análisis de las estructuras lógicas y racionales, sino también con la presencia de campos sensibles, antes visto como sinrazones, como la locura, la poesía y la fe. En este sentido, la experiencia estética crea mundos de la sensibilidad a la artista y científico de la promoción de la experiencia de la temporalidad, saltos de vértigo sistemas no sólo para las emergencias y los nuevos paradigmas de la ciencia, pero los nuevos campos de experimentación artística, como puede verse que la A lo largo del siglo 20.

Palabras clave: Sinrazón 1.Vertigem 2. La construcción del conocimiento 3

\section{A epistemologia e as aberturas para o campo do sensível}

A construção do conhecimento da forma como aprendemos e aceitamos contemporaneamente tem bem pouco tempo de existência. Fomos levados a desenvolver uma preocupação com o exercício de funções que implicou na maneira como compreendemos fazer ciência (DELEUZE, 1992). Observar regularidades, deduzir funções, fazem parte das tentativas de compreender e explicar a realidade nas suas mais variadas formas de manifestação. Naturalmente que os procedimentos de descobertas das funções se tornam mais explícitos quando a busca do conhecimento dirige-se para os fenômenos da natureza física. Por lidar com a matéria e tentar compreender seu comportamento e regularidades que permitem a sustentação do universo conhecido, as Ciências da Natureza criaram os principais alicerces na constituição dos procedimentos de investigação da realidade da forma como compreendemos hoje.

Ao olharmos mais detidamente os movimentos de consolidação das Ciências Modernas entre os séculos 17 e 18 podemos perceber não apenas uma grande ramificação de novos campos de disciplinas do saber, como o desenvolvimento de sistemas teóricos e metodológicos que alicerçam essa reinvenção do mundo (BURQUE, 2003). A epistemologia moderna começava a se estruturar.

Um novo mundo começa a surgir apoiado na fé na razão e, juntamente com essa, ressurge a importância do engenho da técnica. A técnica, que foi vista como atividade menor do pensamento durante grande parte da Idade Média (LOSANO, 1992) volta a assumir importância na criação desse mundo como um elemento gerador de pensamento. Os artefatos técnicos para os artistas do Renascimento permitiram a explosão de uma bolha de pressão de 
um imaginário amordaçado, que a partir de então passou a produzir novas formas de constituição de experiências estéticas.

Um ateliê de um artista renascentista tinha tantos ensaios de obras quanto equipamentos para esses trabalhos. Leonardo da Vinci estudava o movimento das ondas para conseguir maior poder de realismo; Piero Della Francesca e Brunelleschi devoraram a geometria euclidiana, tudo para conseguir melhor apreensão do visível. (DUARTE, 1996, p.47)

As invenções técnicas se multiplicaram criando-se possibilidades para além das atividades artísticas. $\mathrm{O}$ astrolábio, a bússola e os mapas de navegação compuseram um novo repertório de dispositivos técnicos que permitiram a descoberta de novos mundos. Os filósofos iluministas fizeram estourar outra bolha de pressão imaginária e um mundo de pensamentos, de idéias, de reflexões antes proibidas pelas ameaças dos processos inquisitórios ganharam vida em livros fabricados pelo recente invento de Gutemberg. Assim surgiu o trabalho hercúleo de Diderot e D'Alembert da primeira enciclopédia do mundo, uma tentativa de catalogar todos os inventos e descobertas até o século 17.

Essas duas bolhas formadas pela alta pressão de um imaginário constipado por séculos, a criação de engenhos técnicos e a disposição de criação teórica e filosófica, explodiram e uniram-se na formação do espírito científico moderno. A Ciência Moderna aliou a tecnologia com a capacidade de abstração do pensamento, manteve a busca constante das regularidades como princípio e a experimentação e a teorização como construtor das estruturas de explicação do mundo. Uma forma de concepção de real passou a ser inventada com estratégias de mensuração lógicas, racionais e cada vez mais abstratas. O mundo como compreendemos hoje passa a ter um importante agente formador de imagens descritivas e explicativas de um real. A verdade científica apresentada pela razão atingiu o estatuto de valor comparável ao da verdade religiosa de outros tempos.

As visões paradigmáticas se revisam na história do Ocidente de tempos em tempos. Trata-se de um ímpeto de criar um novo mundo coletivamente quando as justas medidas de um mundo antigo não comportam mais as novas sensibilidades em busca de novas experimentações, com novos dispositivos técnicos e o sempre presente desejo de novas experiências. Há um desejo coletivo de reinvenção que impõe novas crises paradigmáticas e a busca por uma composição de realidade que melhor comporte a vontade por conhecer.

De onde partem as primeiras linhas de fuga de um velho regime de constituição do conhecimento? Impossível precisar. Mas quando as linhas de fuga do pensamento vão tomando consistência, o mundo científico é um dos primeiros a sinalizar questões e proposições epistêmicas distintas. Da mesma maneira como ocorreu com a virada do sistema 
Ptolomaico para o Corpenicano, fundador das Ciências Modernas (SLOTERDIJK, 1992), temos assistido, desde o século passado, maiores questionamentos a um mundo exclusivamente racional e a emergência de outras formas de compreensão de realidades e, por conseqüência, a construção de novos mundos.

Poderíamos citar dois caminhos, nos campos da ciência, dessa última reação desejante por novas sensibilidades, que leva à observação de fenômenos instáveis e não mensuráveis, provocando reviravoltas epistemológicas na construção do conhecimento.

Das Ciências da Natureza surgiram observações de fenômenos caóticos que não obedeciam a leis de regularidade, como as da Mecânica. Assim se observou primeiramente com a Termodinâmica e mais à frente em outros espaços das Ciências da Natureza (PRIGOGINE e STENGERS, 1997). Das recém criadas Ciências do Espírito, que veio a ser um nome genérico das Ciências Humanas, surge o interesse de se colocar o homem como objeto de pesquisa, não em sua composição física, mas na composição de suas criações, seus inventos sociais e individuais, de natureza imaginária e concreta. As Ciências do Espírito, como irmã mais nova das Ciências da Natureza, sofreu pressões para que se legitimasse através de um quadro epistemológico derivado das mesmas preocupações e valores das ciências físicas, como mostra Gadamer (1997). Mas apesar das tentativas estruturalistas dos campos da Linguística, da Antropologia e das várias Ciências Cognitivas, algo se construía na observação do humano que ainda manifestava linhas de fuga, componentes não mensuráveis que não permitiam diagnósticos fechados de explicação.

As escolas Pós Estruturalistas compreenderam que no homem a loucura, a crença, a experiência estética e qualquer outra manifestação de desrazão, eram elementos importantes na sua forma de sentir e construir realidades. Ao longo de revisões feitas por disciplinas da Filosofia e História das Ciências se pôde compreender que a própria ciência tinha em seus alicerces a constituição cultural de forma profunda, enriquecida por todas as inspirações do imaginário ${ }^{1}$.

Da produção de sentidos apresentada pela ciência emergiam visões de mundo compostas também por suas desrazões. Algo no humano sempre escapa às tentativas de mapear regularidades definitivas de comportamento. Quando um momento do mundo parece capturar o sentido do homem, forma-se uma nova bolha de pressão imaginária por onde ele escapa, reinventando o sentido da vida. A desrazão passou, então, a ser objeto de interesse

\footnotetext{
${ }^{1}$ Para acompanhar esse debate produzido por vários autores em campos distintos do saber, ver alguns exemplos como DURAND, 1989; FEYERABEND, 2003; MORIN, 1996; ATLAN, 1994.
} 
porque o fenômeno humano não poderia ser conhecido apenas pela tentativa de explicação do que era aparentemente regular.

Entretanto, tais correntes não trouxeram soluções sem colocar novos problemas. Muitos trabalhos científicos de linhas pós estruturalistas afastaram-se completamente de princípios rigorosos das ciências modernas, tendendo ao ensaísmo opinativo, o que os levou ao descrédito da comunidade científica e a acusação de que essas produções eram falsas formas de fazer ciências. Sem a intenção de entrar nos méritos da questão acabamos por nos deparar com um problema de fundo epistemológico. Quando tentamos apresentar o fenômeno humano de maneira mais completa, quando tentamos mostrar que tanto a razão quanto a desrazão são elementos inerentes à construção do conhecimento, tanto no fazer metodológico quanto na ampliação dos objetos que estudamos, nos deparamos com o risco da perda dos contornos do fazer da ciência, nos contornos desenhados pela Modernidade.

As Ciências Modernas criaram soluções para problemas paradigmáticos que dizem respeito ao momento de sua invenção. Não estaríamos agora diante de outra configuração do pensamento que gera outras maneiras de conceber o que seja o conhecimento e como é formado? São novas compreensões de realidade que, por sua vez, concebem não apenas novas formas de olhar as Ciências da Natureza, como também as Ciências do Espírito. Quando não estamos mais sob a mesma pressão religiosa que fez abolir a razão como testemunha do conhecimento, na formação da Idade Média, não criamos oportunidades para compor o fazer científico com o melhor dos dois mundos humanos, o racional e prático, com o evanescente e onírico?

De fato, apesar da capa protetora do estatuto da razão, inúmeras descobertas paradigmáticas das Ciências Modernas se beneficiaram de instantes caóticos no processo de elaboração de seus autores. Como vimos que artistas do Renascimento dispunham dos artefatos técnicos como formas de reflexão e criação de suas obras, assim também os cientistas beneficiam-se de instantes de epifania criativa no seu fazer científico quando acidentalmente são levados a abandonar um sistema coerente e racional como única forma de produção de conhecimentos.

Podemos observar, com isso, que a perda da vigilância da razão, o estabelecimento de tarefas claras e lógicas de avaliação e categorização não foram suficientes para fazer avançar instâncias do próprio processo racional. As constantes gravitacionais, transformadas em leis, puderam ser melhor observadas por Newton quando, forçosamente, teve de se afastar da Universidade de Cambridge e dos centros urbanos ingleses, por conta da Peste Negra. Foi numa região bucólica e longe de seu laboratório, num instante talvez ocioso, que pôde sentir 
na natureza o que ainda não vislumbrava como fundamental de suas pesquisas (MORIN, 1996).

Também Boltzmann concluiu suas idéias sobre a organização da molécula de Benzeno num instante alcoólico em que viu 06 macacos formando um círculo, segurando a cauda um do outro (MORIN, 1996). O astrofísico vietnamita Thrinh Xuan Thuan (1995) narra que tentou finalizar uma equação de seus experimentos antes de sair de férias, e por mais que insistisse em manter seu cronograma de trabalho não conseguia achar a solução. Apenas quando estava com as malas prontas para a viagem, na plataforma do trem, num instante em que a frustração do dever não cumprido abriu espaço para o sentimento das férias, foi acometido pela imagem completa do seu sistema com a devida solução.

A desrazão proporciona a vivência de princípios reorganizadores através de instantes caóticos que impõem a dissipação de fronteiras cognitivas, dos espaços do pensamento conhecido, de marcas viciadas, permitindo uma profunda experiência criativa que aqui podemos compará-la com a experiência estética. Essa forma de experiência estética faz surgir uma nova estrutura, ou um novo conjunto complexo de inter-relações causais que constituem um novo cenário de concepção. Rupturas cognitivas vertiginosas em espaços de percepção por onde, obrigatoriamente, algo de novo emerge.

Começamos a perceber que os processos criativos nas artes e nas ciências partem das mesmas necessidades de desrazões como forma de revelar outras realidades do objeto e do pesquisador. São experiências estéticas espontâneas que emergem quando o forte compromisso com a expressão de um novo mundo afrouxa suas pressões lógicas e permitem que outras instâncias da condição humana participem de sua elaboração. Entramos aqui na observação de características presentes na reformulação epistemológica dos tempos atuais, através da hibridização de técnicas e de capacidades sensíveis do homem, que por sua vez se legitimam como agentes produtores de conhecimento e de novas experiências estéticas.

\section{As interfaces técnicas como produtoras de experiências estéticas}

A produção cultural de parte do século 20 e início do século 21 aponta para a muito comentada discussão em torno dos hibridismos culturais, da mistura de referências que se combinam deslocando a identidade de sujeitos e povos, recriando territorialidades físicas e emocionais em novos contextos de emergência de valores culturais.

Não é difícil perceber que o eixo das reflexões contemporâneas monta-se a partir de um intenso diálogo de contraposição com uma das feições da tradição moderna: a fixação de 
fronteiras e o estabelecimento de identidades. Porém, neste diálogo de contraposição, para além das análises sócio-culturais, a obsolescência das fronteiras e o trânsito de identidades serviram como metáforas para grandes revisões epistemológicas, para novas práticas científicas, e também para toda uma outra práxis artística. Novas práxis que, consequentemente, engendram novas poéticas.

Em tempos em que nações separam-se, reinventando territórios; migrações em massa miscigenam povos e reinventam costumes; mega-empresas se fundem, reinterpretando deslocamento de capitais; as produções artísticas e os meios de comunicação de massa também seguem o fluxo de recriação de percepções estéticas através de suas fusões e hibridismos formais que levam, por consequência, a novas construções narrativas e novas construções de percepção do tempo em seus meios. Novos fenômenos narrativos, nascidos do movimento de nomadia, de abandono de territórios anteriormente bem demarcados, onde as linguagens perderam a precisão de suas identidades e encontram-se turvas, gerando novas expressões ainda não consolidadas.

Por narrativa compreendemos a forma de construção de uma mensagem que estabelece espaço e temporalidade próprios. A mensagem é a ordenação de um conteúdo neste espaço específico, criado por ela. Sua estrutura é dependente de um tempo e é nele que se desenvolve. É através desta temporalidade que seu conteúdo acontece. Este conteúdo se deixa ver neste espaço, e apenas neste espaço. Em outras palavras, a narrativa recria realidades. Logo, os hibridismos formais das expressões estéticas e materiais das artes e dos mass media recriam narrativas e isso permite deslocamentos e reconstruções espaço-temporais de seus conteúdos. Esse movimento aponta o que compreendemos como característica fundante das narrativas contemporâneas.

Como fenômenos narrativos contemporâneos, temos em mente os pontos de bifurcação das linguagens tradicionais. Estes pontos de bifurcação representam o momento em que as linguagens entram em colapso para que narrativas ainda sem território bem demarcado surjam e, assim, engendrem novas realidades.

Vislumbramos inúmeros casos onde as linguagens se bifurcam entrando em entropia. O cinema, por exemplo, entra em entropia e se bifurca com o surgimento do vídeo-clip e do vídeo game. Estes dois fenômenos narrativos possuem componentes oriundos do cinema, porém reposicionam estes componentes somando-os a outros advindos de novos avanços tecnológicos. As artes plásticas se bifurcam entrando em entropia quando fazem uso de câmaras de vídeo, criando narrativas híbridas de cinema documentário com poéticas performáticas. As artes plásticas também se bifurcam quando fazem uso da fotografia e de 
manipulações digitais, criando verdadeiros curto-circuitos entre registro documental e composição imaginária, entre realidade e ficção. A bifurcação do teatro ocorre quando o status de "representação" passa a se confundir com o de "apresentação", quando atores não simulam dores e prazeres, porém, se impõem situações de dor e prazer reais. Por outro lado o teatro pode aproximar-se da televisão através dos espetáculos revista ou dos programas de auditório. A fotografia desloca-se em sua força expressiva com elementos narrativos das artes plásticas e da hipermídia. A estética da produção videográfica digital invade a estética cinematográfica criando o cinema digital, um produto híbrido e ainda sem definição estética clara.

A própria linguagem da ciência também possui áreas de entropia e bifurcação. Destas bifurcações vêm surgindo híbridos de ficção e ciência. Redefinições vêm se impondo sobre temas até pouco tempo impensáveis dentro da prática científica. Quais os limites entre investigação e criação? Sabemos que os métodos e instrumentos de investigação científica interagem com seus objetos e são co-participantes na criação destes mesmos objetos. A ciência não seria, portanto, assim como a arte, um processo investigativo de suas próprias realidades?

Em período moderno a literatura científica nunca acolheu bons olhos as experiências ficcionais nos seus ensaios. Subjetividade e objetividade, universalidade e particularidade, investigação e criação, história e mito foram segregados em territórios autônomos e antitéticos, dentro do espírito próprio da modernidade.

A literatura, por sua vez, viu crescer dentro de si a ficção científica que, sem pudor, incorporava os discursos e temas científicos. Porém é interessante atentar que as reações vindas do território específico da literatura não foram muito diversas daquelas da ciência. Em um movimento de igual repúdio, delegou a este tipo mestiço de narrativa o lugar de "subliteratura", de "entretenimento de cunho científico", etc. Títulos honoríficos degenerados com os quais, a rigor, ainda convivemos.

Se o paradigma moderno da especialidade e da separação dos saberes agiu sobre a ciência, não foi diferente o que agiu sobre o território da arte. O movimento em busca de uma identidade e territórios fixos e definitivos fica igualmente claro na produção de artes plásticas na primeira metade do século 20. A pintura entra em crise com a invenção da máquina fotográfica. Montada como método de captura do real desde a renascença, a pintura vê-se obrigada a refletir sobre seus motivos constitutivos, e será através de sua autonomia, de sua "purificação" que procurará alicerçar sua nova identidade para, assim, cercar seu novo território. Piet Mondrian construirá verdadeiras pérolas ensaísticas em defesa da então 
nascente pintura abstrata geométrica e o futuro movimento concreto. Toda sua defesa e prescrições de condução da pintura falam sobre a busca do que seriam os fundamentos próprios e intransferíveis da linguagem pictórica.

Nas artes plásticas a especialidade e a segregação se tornaram crescentemente minuciosas, chegando a ponto de tornar o desenho, a pintura, a gravura, a escultura, a instalação, a performance, o happening, a vídeo de arte, a body art, linguagens específicas, donatárias de regras e pré-requisitos muito bem demarcados.

Não será diferente com relação ao cinema. Linguagem mestiça por origem, o cinema causará problemas para seus analistas desde seu surgimento. O filósofo Evaldo Coutinho (1996) seguirá à risca a norma modernista quando prescreve que a mudez e a ausência de colorização são condições básicas para a instituição da linguagem cinematográfica. O som seria especialidade da música e, sendo articulado em palavras, cairia nas malhas da literatura; a cor, por sua vez, também descaracterizaria a nova linguagem tendo em vista que é matéria própria da pintura e das artes plásticas.

Há algumas décadas estas verdades perderam solidez e as "claras" demarcações territoriais de expressões e construção de sentidos foram abaladas. $\mathrm{O}$ estranhamento que esse deslocamento provoca na percepção do mundo ocorre, entre outros motivos, pela combinação de temporalidades e espacialidades até então bem separadas e definidas.

\section{A padronização do tempo na experiência estética}

A multiplicidade de experimentações temporais é contingência natural dos seres humanos. Como temos um aparelho cognitivo que nos permite criar a consciência, podemos também criar o tempo, que determina a velocidade com que a consciência percebe objetos no mundo. O natural é a diversidade do tempo; é natural sentir a aceleração e o retardo como contingências próprias de diversas vivências. Seja pela necessidade de respostas rápidas aos estímulos convocados pela vida, seja por uma plácida contemplação de mundo, seja pelo silêncio agitado do estado brutal de criação artística, seja pelo estado de silêncio total da mente em estado meditativo. São as infinitas possibilidades naturais de cavalgar o tempo, que nunca se põe como algo homogêneo.

Entretanto, a homogeneização do tempo pode ser representada. Essa padronização se expressa contemporaneamente tanto nos produtos midiáticos quanto nos produtos artísticos. Mudam-se as histórias, os personagens, mas o ritmo no qual sentimos a construção da experiência narrativa não sofre muitas oscilações. Existe uma espécie de gradiente de 
percepção temporal dentro do qual os produtos podem ser mais facilmente assimilados, logo comercializados, por uma massa de mentes que gradativamente acostuma-se com certa normalidade da expressão temporal desses meios.

O hábito de um gradiente temporal de experiência estética transmitido de geração em geração provoca um profundo condicionamento que leva à resistência de outras formas de expressão temporal. Qualquer construção estética que saia desse gradiente provoca algum tipo de incômodo, como irritação, ou às vezes desinteresse geral, ou sentenciamentos de gostos, ou sonolência. A padronização da percepção estética do tempo funciona como um tipo de morfina, um anestésico para a condição natural da diversidade do tempo, o que leva a possibilidades de totalitarismos de gosto. O prazer por se sentir reconhecido na semelhança diminui a disposição pela potência de vida da diversidade como garantia de circulação tautológica do capital. A padronização, a semelhança, acaba por fim agindo politicamente como uma espécie de morfina cognitiva.

Mas como a abertura para os espaços de desrazão faz parte de uma constante dos seres humanos que sempre promovem brechas para reestruturação de seus sistemas, a morfina cognitiva está sempre em risco. Quando a experiência da diversidade do tempo não fez parte de um processo de formação de um indivíduo ou de um grupo, sua experimentação pode vir a ser desconfortável, porque pode implicar numa ruptura vertiginosa.

Referimo-nos aqui a uma experiência estética que promova imersão num tempo diverso, e que esse por sua vez consuma quem o experimenta. Na concepção de Dewey (DEWEY, 2005), não se trata de uma relação de conclusão, de concluir algo da obra, não se trata de finalizar a obra e ter uma opinião de gosto a seu respeito na sua conclusão. Para Dewey a idéia de concluir algo da obra ainda implica numa distância da experiência. A experiência estética ocorre na consumação do indivíduo pela obra, ou melhor, em deixar-se ser consumido no encontro com o objeto, ou na realização do fenômeno de encontro. O que ocorre na consumação é que uma vivência temporal se distingue, ela emerge pelo encontro de campos sensíveis construídos sobre plataformas temporais distintas. Quando um fenômeno de consumação na experiência estética ocorre com qualquer pessoa ou grupo social condicionado a gradientes de percepção temporal, ocorre uma ruptura que compreendemos através da idéia de vertigem.

A vertigem é promovida por uma relativização abrupta do sistema mental em sua estrutura de compreensão do tempo e do espaço. Essas rupturas podem ser de leves fissuras que causam incômodos e lentamente geram reflexões até fortes abalos emocionais, choques geradores de perplexidade. A esse susto, ou impacto, quando provoca admiração estaríamos 
próximos do conceito de Sublime, apresentado por Kant, essa forma de prazer negativo, seu espanto, movido à rejeição e sedução (KANT, 2002). Mas a vertigem em princípio não é nem boa nem má. Não tem compromisso com o prazer ou o desprazer, nem com elevação espiritual daquele que a experimenta, ela é simplesmente uma ruptura de um padrão cognitivo e emocional. Ela não se prolonga por muito tempo porque é natural que o sistema se recupere e crie novas referências ou refaça as antigas. A vertigem é uma forma de experiência estética que abre campos de experimentação artística trazendo um sopro de novidade nos ambientes de criação tanto artísticos quanto científicos. O torpor de vertigem é um momento propício à emergência de realidades temporais e espaciais distintas.

A vertigem demonstra a necessidade natural da espécie humana pela impermanência de suas estruturas de conhecimento ou interpretação de realidades. Isso é importante, sobretudo, para a ciência que quando não se permite a naturais revisões tende a transformar-se em dogma. O natural da ciência é ser biodegradável (MORIM, 1996). As estruturas de conhecimento periodicamente sofrem transformações, revisões que nascem de aberturas a novas expressões do conhecimento. Essas expressões são linhas de fuga que fazem explodir bolhas de pressão do imaginário contido, dando origem a novas estruturas, a novas combinações de artes e saberes, como as que experimentamos hoje. O que os paradigmas contemporâneos de construção do conhecimento nos apresentam é a possibilidade de criação do mundo em que os fenômenos racionais e irracionais se misturam e proporcionam a emergência de realidades. A desrazão é colocada como aliada epistemológica, pois a experiência estética é assumida nesses sistemas como fundamental na produção de conhecimento.

\section{Referências}

ATlAN, Henri. Com Razão ou Sem Ela - Intercrítica da Ciência e do Mito. Lisboa: Instituto Piaget, 1994.

BURQUE, Peter. Uma História Social do Conhecimento - de Gutenberg a Diderot. Rio de Janeiro: Zahar, 2003.

COUTINHO, Evaldo. A Imagem Autônoma. São Paulo: Editora Perspectiva, 1996.

DELEUZE, Gilles. O que é Filosofia? Rio de Janeiro: Editora 34, 1992.

DEWEY, John. Art as Experience. New York: Perigee, 2005.

DUARTE, Eduardo. Fondu-Enchaîne - vida, morte e ressurreição da aura. In: Revista Icone, 1996. DURAND, Gilbert. As Estruturas Antropológicas do Imaginário. Lisboa: Editora Presença,1989. 
FEYERABEND, Paul. Contra o Método. São Paulo: UNESP, 2007.

GADAMER, Hans-Georg. Verdade e Método I: traços fundamentais de uma hermenêutica filosófica. 6 ed. Trad. Flávio Paulo Meurer. Petrópolis, RJ: Vozes, Bragança Paulista, SP: Editora Universitária São Francisco, 1997.

KANT, Immanuel. Crítica da Faculdade do Juízo. Rio de Janeiro: Forense Universitária, 2002.

LOSANO, Mario G. Histórias de Autômatos - Da Grécia Clássica à Belle Époque. São Paulo: Companhia das Letras, 1992.

MATURANA, Humberto; VARELA, Francisco. A Árvore do Conhecimento. Campinas: Editorial Psy II, 1995.

MORIN, Edgar. Ciência com Consciência. Rio de Janeiro: Bertrand Brasil, 1996.

PRIGOGINE, Ilya; STENGERS, Isabelle. A Nova Aliança. Brasília: Editora UNB, 1997.

SLOTERDIJK, Peter. A Mobilização Copernicana e o Desarmamento Ptolomaico. Rio de Janeiro: Tempo Brasileiro, 1992.

THUAN, Trinh Xuan. Um Astrophysicien. Paris: Flammarion. 1995.

Original recebido em: 28/03/2011

Aceito para publicação em: 12/09/11

Resumo sobre o autor:

Doutor em Ciências Sociais pela Pontifícia Universidade Católica de São Paulo (2002). Professor adjunto do Dept. de Comunicação Social da Universidade Federal de Pernambuco. Areas de atuação: Antropologia, com ênfase em Epistemologia. Comunicação e Experiências Estéticas. Atuando principalmente nos seguintes temas: cinema, imaginário e fotografia.

http://buscatextual.cnpq.br/buscatextual/visualizacv.do?id=K4760045P0 